Gut, $1989,30,820-825$

\title{
Does dietary fibre stimulate intestinal epithelial cell proliferation in germ free rats?
}

\author{
R A GOODLAD, B RATCliffe, J P FORDHAM, AND N A WRIGHT
}

From the Cancer Research Campaign Cell Proliferation Unit, Department of Histopathology, Royal Postgraduate Medical School, DuCane Road, London, and Polytechnic of North London, Holloway Road, London, and AFRC Institute of Food Research, Reading, Berks

SUMmaRY The aim of the present experiment was to investigate the role of hind gut fermentation in the proliferative response of the intestinal epithelium to dietary fibre. We have previously shown that refeeding starved rats with an elemental diet supplemented with fermentable dietary fibre (but not inert bulk) is capable of stimulating intestinal epithelial cell proliferation throughout the gastrointestinal tract. Three groups of 10 germ free (GF) rats and three groups of 10 conventional (CV) rats, were used. All groups were starved for three days and then refed for two days with either an elemental diet (Flexical); Flexical plus 30\% kaolin; or Flexical plus $30 \%$ of a fibre mixture. Cell production was determined by the accumulation of vincristine arrested metaphases in microdissected crypts. There was no significant difference between refeeding the rats with an elemental diet alone or with kaolin supplementation, however, the addition of fibre in $\mathrm{CV}$ rats was associated with a significant increase in intestinal crypt cell production rate in both the small intestine $(p<0 \cdot 01)$ and the colon $(p<0 \cdot 001)$. This marked proliferative effects of fibre was abolished in the GF rats. It can be concluded that it is the products of hind gut fermentation, not fibre per se that stimulate intestinal epithelial cell proliferation in the colon and small intestine.

The term 'dietary fibre' is generally used as a broad (but useful) description for any non-starch polysaccharide not degraded by mammalian endogenous secretions; thus encompassing the glucose chains of cellulose and non-cellulosic polysaccharides, soluble and insoluble simple sugars, hemicellulose, pectic substances and lignin.' Fibre is broken down by the microflora of the hind gut of monogastric animals such as man to produce short chain fatty acids (SCFA's), mainly in the form of acetic, propionic, and butyric acid, which can be metabolised by the colonic epithelium and by the liver, ${ }^{2}$ and may constitute about $10 \%$ of the daily energy intake, even in the fibre deficient 'Western' diet. ${ }^{3}$

The intestinal epithelium is a very dynamic tissue which is capable of adapting to a wide variety of situations by adjusting the rates of cell production in its well defined reproductive zones. ${ }^{4}$ Feeding the low bulk chemically defined 'elemental diets' is associated with intestinal atrophy and decreased cell pro-

\footnotetext{
Address for correspondence: Robert A Goodlad, PhD, Imperial Cancer Research Fund, Histopathology Unit, 35-43 Lincoln's Inn Fields, London WC2A 3PN.

Accepted for publication 7 November 1988.
}

liferation, especially in the distal gut. ${ }^{56}$ Although this has been attributed to the lack of non-absorbable 'bulk',-9 it is more likely to be the consequence of the removal of fermentable fibre. ${ }^{610}$ Refeeding starved animals can potentiate the effects of different dietary components, and provides a very useful model for the study of intestinal adaptation..$^{112}$ Refeeding starved rats with a fibre free elemental diet supplemented with fermentable fibre stimulates intestinal epithelial cell proliferation in the colon and in the small intestine,${ }^{13}$ whilst the addition of inert bulk has no such effect. Fibre, but not bulk, also has a similar effect in mice fed continuously. ${ }^{6}$

These proliferative effects could either be the result of the direct effects of fibre itself or to the products of its breakdown by the complex microbiological flora of the caecum and colon. ${ }^{14}$ If the latter was indeed the case one would expect that the proliferative effect on the intestinal epithelium would be abolished in GF animals. The present study describes the proliferative effects of refeeding GF rats, or rats with a CV intestinal flora, a fibre free elemental diet supplemented with kaolin or with a fermentable fibre mixture. 


\section{Methods}

EXPERIMENTAL PLAN

Three groups of $\mathrm{CV}$ rats and three comparable groups of GF rats were starved for three days and then refed for two days. The first pair of groups were refed with $15 \mathrm{~g} / \mathrm{rat} /$ day of Flexical (Mead Johnson, Slough), the second were refed with flexical plus $30 \%$ w/w kaolin and the third pair of groups were refed with Flexical plus $30 \%$ of a fibre mix. The fibre mix comprised of $10 \%$ of the dietary mucilage from the ispaghula husk (Reckitt \& Coleman) and $90 \%$ of the wheat grain fibrous extract, Trifyba (Labaz Sanofi. Wythenshawe, Manchester; hemicellulose $40 \%$, cellulose $20 \%$, lignin $15 \%$, and pectin $5 \%$ ). The animals had free access to water at all times.

After two days of refeeding the rats were weighed, injected with vincristine and killed at timed intervals by ether anaesthesia followed by exsanguination. The intestines were removed, rinsed, blotted, weighed and one centimetre samples from defined sites were fixed in Carnoy's fluid.

\section{A NIMALS}

The rats were the offspring of a colony of GF Lister Hooded or a colony of genetically similar $\mathrm{CV}$ animals. The mean weight at the beginning of the experiment was $200 \mathrm{~g}$, with no significant difference between any of the groups. All rats were between five and six weeks old at the start of the experiment. The animals had been maintained on a standard laboratory diet (PRD, Spillers) post weaning. Individuals were randomly assigned to a particular dietary treatment within either GF or CV environments.

\section{HOUSING}

Both CV and GF rats were housed in stainless steel isolators of the type described by Gustafsson. ${ }^{15}{ }^{16}$ Rats were in groups of 10 per isolator. The cages were stainless steel with wire grid floors and were maintained without bedding.

GERM FREE TECHNIQUES

All CV and GF rats were maintained in isolators which were supplied with filtered, sterile air. All diets were sterilised by irradiation at a level of $50 \mathrm{kGy}$ from $a^{(n)}$ Co source and water was autoclaved. The isolators containing the GF rats were maintained with appropriate sterile techniques; GF status was monitored by taking swabs from the isolators and examining them by the techniques described by Fuller. ${ }^{17}{ }^{1 \times}$

CRYPT CELL PRODUCTION RATE

Rats were injected with vincristine sulphate $(1 \mathrm{mg} / \mathrm{kg}$ intraperitoneally; Tillots Laboratories, Henlow, Bedfordshire, UK) at 0900 hours and killed at timed intervals 30 to 180 minutes later. Samples of the small intestine and colon (defined by their percentage length of the entire small intestine or colon) were fixed in Carnoy's fluid and stored in $70 \%(\mathrm{v} / \mathrm{v})$ ethanol. They were later stained with the Feulgen reaction. Intestinal and colonic crypts were displayed by microdissection and gently squashed with a coverslip. The number of arrested metaphases in 10 small intestinal crypts or 20 colonic crypts were counted and the mean values plotted against time since injection. The slope of the line was then fitted by linear regression to give the crypt cell production rate (CCPR) and its standard error. ${ }^{14}$

STATISTICAL ANALYSIS

All results are presented as the mean (standard error) of the mean. Data were tested by a two-sided $t$ test, or by two way analysis of variance where the data was classified by two factors, diet and microflora. In the latter case it is possible for one of the two factors to alter the effect of the other; this is measured by an interaction effect. Lines were fitted by least squares linear regression.

\section{Results}

The effects of the different diets and of intestinal flora on total body weight, intestinal length, and the wet weight of the main regions of the gastrointestinal tract are presented in the Table, which also summarises the results of two-way analysis of variance on the above data. The GF groups were significantly heavier than the $\mathrm{CV}$ rats, but these animals had the grossly distended fluid filled caeca associated with GF status ${ }^{20}$ which would have contributed to the increased body weight. There was a significant tendency for the body weight to be less in those groups fed the supplemented diets.

Two way analysis of variance showed a small effect of diet on stomach weight, which was less in the fibre supplemented group. No effect of microflora was noted. The small intestine, caecum and colon were all significantly heavier in the GF groups. The hypertrophy of the caecum was particularly pronounced. No significant effect of diet was noted in the small intestine and caecum, but a very highly significant effect was seen in the colon, where the colon weight increased in the fibre fed animals, especially the CV ones. A significant interaction between the effects of diets and microflora was observed. The colon length mirrored the colon weight changes.

The crypt cell production rate of the proximal small intestine of the CV group fed fibre was significantly increased when compared with the group fed the elemental diet alone or plus kaolin. No such effect was seen in the GF animals (Figure.). 
Table 1 The effects of the various treatments on the mean body weight, intestinal wet weight and the length of the small intestine and the colon

\begin{tabular}{|c|c|c|c|c|c|c|}
\hline \multirow[b]{2}{*}{ Measurement } & \multirow[b]{2}{*}{ Diet } & \multirow[b]{2}{*}{ Diet+kaolin } & \multirow[b]{2}{*}{ Diet + fibre } & \multicolumn{3}{|c|}{$\begin{array}{c}\text { Two-way analysis of variance } \\
\text { Effects of }\end{array}$} \\
\hline & & & & Diet & Microflora & Interaction \\
\hline \multicolumn{7}{|c|}{ Body weight (g) } \\
\hline $\mathrm{CV}$ & $226 \cdot 4(6 \cdot 9)$ & $211 \cdot 2(7 \cdot 7)$ & $211 \cdot 9(7 \cdot 0)$ & \multirow{2}{*}{$*$} & \multirow{2}{*}{$\dagger$} & \\
\hline GF & $246 \cdot 8(5 \cdot 4)$ & $231 \cdot 3(9 \cdot 0)$ & $221 \cdot 2(7 \cdot 8)$ & & & \\
\hline \multicolumn{7}{|c|}{ Weight stomach (g) } \\
\hline $\mathrm{CV}$ & $1 \cdot 183(0 \cdot 038)$ & $1 \cdot 113(0 \cdot 060)$ & $1 \cdot 108(0 \cdot(034)$ & \multirow[t]{2}{*}{ * } & & \\
\hline GF & $1 \cdot 194(0 \cdot(050)$ & $1 \cdot(031(0 \cdot 046)$ & $1 \cdot 120(0 \cdot 043)$ & & & \\
\hline \multicolumn{7}{|c|}{ Length small intestine $(\mathrm{cm})$} \\
\hline $\mathrm{CV}^{\circ}$ & $104 \cdot 6(1 \cdot 5)$ & $103 \cdot 1(1 \cdot 3)$ & $90 \cdot 6(9 \cdot 0)$ & & \multirow{2}{*}{$\dagger$} & \\
\hline GF & $106 \cdot 1(1 \cdot 7)$ & $107 \cdot 7(1 \cdot 6)$ & $110 \cdot 5(7 \cdot 8)$ & & & \\
\hline \multicolumn{7}{|c|}{ Weight small intestine (g) } \\
\hline $\mathrm{CV}^{\circ}$ & $6 \cdot 168(0.253)$ & $5 \cdot 721(0 \cdot 242)$ & $5.986(0 \cdot 179)$ & & \multirow{2}{*}{$\dagger$} & \\
\hline GF & $6 \cdot 624(0 \cdot 150)$ & $6 \cdot 573(0 \cdot 340)$ & $6 \cdot 675(0 \cdot 321)$ & & & \\
\hline \multicolumn{7}{|c|}{ Weight caecum (g) } \\
\hline $\mathrm{CV}$ & $0 \cdot 810((0 \cdot 036)$ & $0 \cdot 726(0 \cdot(039)$ & $0 \cdot 714(0 \cdot 031)$ & & \multirow{2}{*}{$\ddagger$} & \\
\hline GF & $1.811(0 \cdot 059)$ & $1 \cdot 806(0 \cdot 105)$ & $1 \cdot 795(0 \cdot 083)$ & & & \\
\hline \multicolumn{7}{|c|}{ Length colon $(\mathrm{cm})$} \\
\hline $\mathrm{CV}$ & $13 \cdot 5(0 \cdot 4)$ & $14 \cdot 1(0 \cdot 2)$ & $14 \cdot 7(0 \cdot 3)$ & \multirow{2}{*}{$\ddagger$} & \multirow{2}{*}{$\ddagger$} & \multirow{2}{*}{$*$} \\
\hline GF & $15 \cdot 4(0 \cdot 4)$ & $15 \cdot 5(0 \cdot 2)$ & $18 \cdot 0(0 \cdot 5)$ & & & \\
\hline \multicolumn{7}{|c|}{ Weight colon (g) } \\
\hline $\mathrm{CV}$ & $0 \cdot 860(0 \cdot(030)$ & $0.992(0 \cdot(049)$ & $1 \cdot 221(0 \cdot 060)$ & \multirow{2}{*}{$\ddagger$} & \multirow{2}{*}{$\dagger$} & \multirow{2}{*}{$\dagger$} \\
\hline GF & $1 \cdot 085(0 \cdot 031)$ & $1 \cdot 143(0 \cdot 040)$ & $1 \cdot 155(0 \cdot 051)$ & & & \\
\hline
\end{tabular}

*Significantly different $(\mathrm{p}<0 \cdot 05)$; $†$ Significantly different $(\mathrm{p}<0 \cdot 01)$; $\ddagger$ Significantly different $(\mathrm{p}<0 \cdot 001)$.

Standard error of the means are shown in parentheses.

This proliferative effect of fibre in the CV rats was more pronounced in the distal than in the proximal small intestine, with the cell production rates of the fibre fed group being almost doubled $(p<0 \cdot 01)$ when compared with the unsupplemented group. The proliferative effect of fibre was even more pronounced in the colon of the $\mathrm{CV}$ rats where there was a sixfold increase in the CCPR $(p<0 \cdot 001)$. No such effect was seen in any of these sites in the GF groups.

\section{Discussion}

The results of this study confirm the proliferative effect of fibre on intestinal epithelial cell production in $\mathrm{CV}$ rats, and the lack of any proliferative response in the GF rats implies that it must be the fermentation of fibre in the hind gut that is the cause of this proliferation. The main product of the bacterial breakdown of fibre are the short chain fatty acids (SCFA's), and there is some evidence that these are indeed trophic to the intestine in vivo. ${ }^{1+2122}$

The changes in crypt cell production noted in the small intestine and colon were very pronounced, which was reflected by the significant changes in intestinal weight observed, despite the short duration of refeeding. Two way analysis of variance showed the presence of significant changes in stomach weight with diet, which reflected a slight decrease in tissue weight with fibre ingestion. All areas of the intestine were heavier in the germ free rats, and this led to a significant microflora effect in all areas studied except the stomach. The most dramatic effect of germ free status was the massive increase in caecal weight, which increased 2.4 times and even this still does not reflect the magnitude of the caecal volume increase; Gustafsson $^{20}$ quotes a five-fold volume increase in the caecal contents of the GF rat (for a doubling of tissue weight) and a 30-fold increase in the luminal mucus content. Caecal enlargement is also seen in CV rats fed large amounts of non-absorbed large molecules, or in those fed antibiotics ${ }^{23}$ and this does not appear to depend on the luminal osmolarity..$^{24}$

It is interesting that no effect of diet on the caecum was noted, whereas the colon length and weight both showed a highly significant effect of both diet and microflora. This increase in colon weight noted in the $\mathrm{CV}$ rats, although quite dramatic, however, was not nearly as pronounced as the increase in CCPR; nevertheless, if the experiment had continued for longer the weight change could perhaps have been equally pronounced. Alternatively the changes 

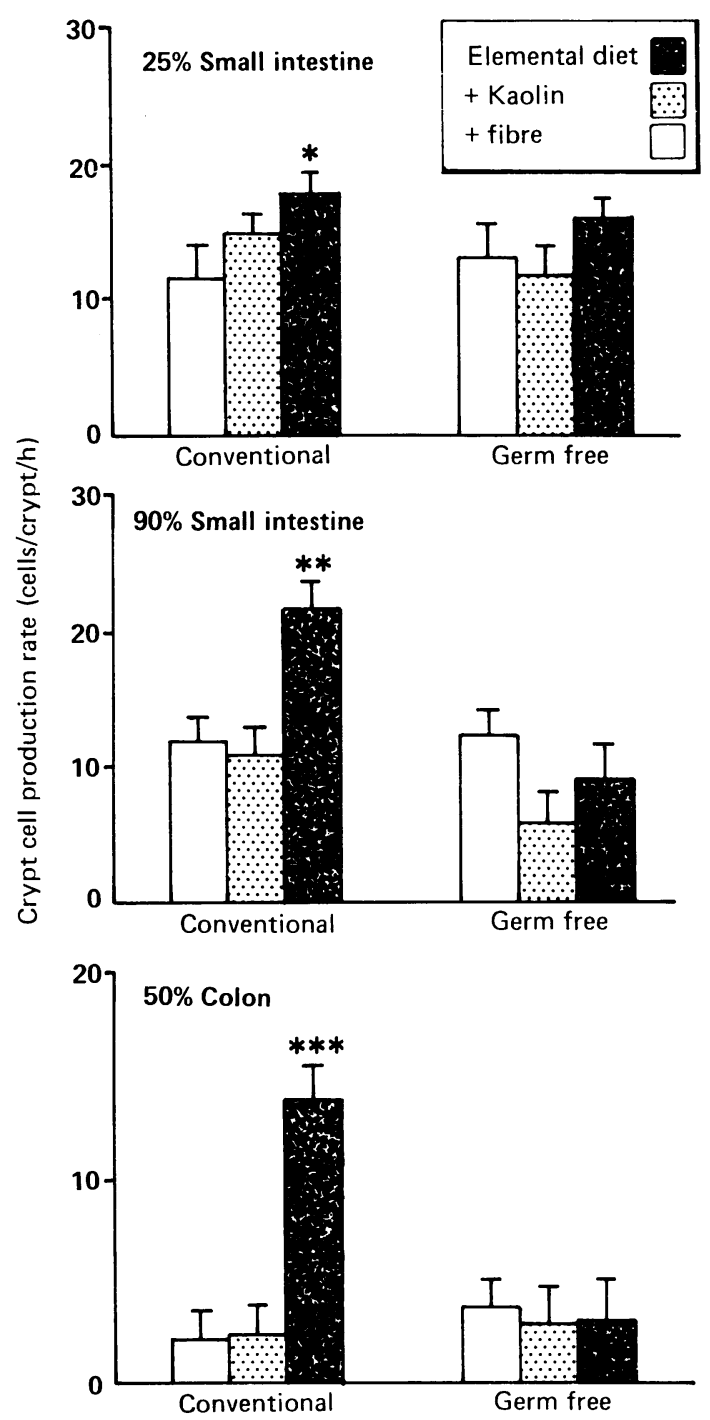

Figure Effects on crypt cell production $(C C P R)$ of refeeding various diets to starved rats. Conventional ( $C V)$ or germ-free $(G F)$ animals were refed with an elemental diet, or with the same diet supplemented with either kaolin or a fermentable fibre mixture. The sites in the intestine were identified by their relative position in the gut. *Significantly greater than the respective group fed the elemental diet $(p<0 \cdot 05) ; * *$ Significantly greater than the respective group fed the elemental diet $(p<0 \cdot 01) ; * * *$ Significantly greater than the respective group fed the elemental diet $(p<0 \cdot 001)$.

observed may represent the peak of an adaptive response, and a lesser effect would be seen in a chronic system; however consistent longterm changes would still be expected..$^{625}$

The proliferative effect is only one of the many biological effects of fibre. Poorly fermentable fibre may abrade the intestine and stimulate increased cell loss, as cellulose powder has been reported to decrease villus length in GF mice, whilst it increased length ${ }^{26}$ and turnover rate ${ }^{27}$ in $\mathrm{CV}$ mice. The GF intestinal villi are usually enlarged, perhaps because of decreased cell loss. ${ }^{28}$ The use of villus length is not, however, the ideal estimator of intestinal morphology. ${ }^{6}$ Fibre may also dilute or bind carcinogens and alter bile acid and cholesterol levels. ${ }^{1} \mathrm{~A}$ further effect of fibre, especially when from the brassicas, is to stimulate the induction of xenobiotic metabolising enzymes..$^{29}$ Other repercussions of fibre intake include delaying gastric emptying and consequently damping the glycaemic response, stool softening, reducing digesta transit times and increasing stool output. Some fibres, especially those rich in phytic acid, bind minerals and thus render them unavailable to the animal. The microbial breakdown of fermentable fibre leads to the production of SCFA's which in turn will also have many effects; these include lowering luminal $\mathrm{pH}$ (which in turn increases SCFA uptake, as they are more readily absorbed in the unionised form), and increasing water absorption. In addition fibre can alter the intestinal flora, stimulate mucous production, increase vitamin $\mathrm{K}$ absorption, increase mucosal blood flow, increase motor activity, ${ }^{30}$ and alter urea and ammonia concentration.'

The extent of fibre fermentation in the colon, of monogastric animals, including man is only recently being appreciated.' 2 Although the metabolism of short chain fatty acids is not as important as that seen in fore-gut fermenters where over $70 \%$ of the daily energy intake may be absorbed in the form of SCFA's ${ }^{31}$ (and the more fermentable the diet the greater the epithelial cell proliferation in the foregut),,$^{32}$ recent estimates suggest that even on the relatively low fibre diet of the Western world SCFA production contributes significantly to the daily energy intake in man. ${ }^{3}$ It should be borne in mind that SCFA production will occur even when no fibre is ingested, as intestinal mucus and other materials will still arrive at the hind gut, thus the SCFA concentration (but not production) in dogs fed only on meat is similar to that seen in hind gut fermenting herbivores. ${ }^{33}$

The weight of bacteria in the colon is equivalent to, or greater, than that of several major body organs, and there are more bacteria in the colon than there are cells in the human body. ${ }^{20}$ The bacterial content of the colon is around $10^{10}-10^{11}$ per $\mathrm{ml}$ whereas in the terminal ileum it is $10^{7}-10^{\times},{ }^{211}$ therefore although there is some fermentation in the ileum, ${ }^{33}$ SCFA levels are very low, so that the proliferative response observed is unlikely to be a direct effect of SCFA production, 
suggesting a systemic effect which may be direct or may be moderated via some other humoral agent. There is considerable evidence that many adaptive responses are strongly influenced by blood borne agents. ${ }^{34}$

It has been reported that SCFA infusion into the colon stimulates mitotic indices in the jejunum,${ }^{14}$ but in vitro studies show no direct effect upon isolated intestinal tissue. ${ }^{22}$ We have previously shown a good correlation between plasma enteroglucagon and PYY in animals fed fibre mixtures of varying degrees of fermentability, and the changes in these hormones in GF rats will be described later.

The biological significance of this proliferative effect of fermentable fibre and SCFA's is not as yet clear, as it is only one of the many effects of fibre now known. None the less, this effect warrants further study, especially in light of the observed relationship between hyperplasia and the promotion of carcinogenesis in experimental animals. ${ }^{4}$ Feeding carcinogen treated rats a high fibre diet has been shown to enhance colon carcinogenesis; ${ }^{35}$, th nevertheless, other workers have found the converse. ${ }^{37}{ }^{38}$ Although such models usually only study the end yield of a complex multistage system, they none the less sound a note of warning, particularly in light of the current advocacy of high fibre diets.

We thank the Cancer Research Campaign for their financial assistance and $\mathrm{Mr} \mathrm{W}$ Lenton for his technical assistance. BR and JPF were supported by the AFRC.

\section{References}

1 Heaton KW. Dietary fibre in perspective. Hum Nutr Clin Nutr 1983; 37: 151-70.

2 Cummings JH, Pomare EW, Branch WJ, Naylor CPE, Macfarlane GT. Short chain fatty acids in human large intestine, portal hepatic and venous blood. Gut 1987; 28: 1221-7.

3 McNeil NI. The contribution of the large intestine to energy supplies in man. Am J Clin Nutr 1984; 39: 33842.

4 Wright NA, Alison MR. The biology of epithelial cell populations. Vol 2. Oxford: Clarendon Press, 1984.

5 Janne P. Carpenter Y, Willems G. Colonic mucosal atrophy induced by a liquid elemental diet in rats. $\mathrm{Am} \mathrm{J}$ Dig Dis 1977; 22: 808-12.

6 Goodlad RA, Wright NA. The effects of addition of cellulose or kaolin to an elemental diet on intestinal cell proliferation in the mouse. Br J Nutr 1983; 50: 91-8.

7 Dowling RH, Reicken EO, Laws JW, Booth CC. The intestinal response to high bulk feeding in the rat. Clin Sci 1969; 32: 1-9.

8 Ryan GP, Dudrick SJ, Coleland EM, Johnson LR. Effects of various diets on colonic growth in rats. Gastroenterology 1977; 77: 658-63.
9 Bristol JB, Williamson RCN. Large bowel growth. Scand J Gastroenterol 1983; 19 [suppl 93]: 25-34.

10 Jacobs LR, Lupton JR. Effects of dietary fibres on rat large bowel mucosal growth and cell proliferation. $A m J$ Physiol 1984; 246: 378-85.

11 Stragland JJ, Hagemann RF. Dietary influence on colonic cell renewal. Am J Clin Nutr 1977; 30: 918-23.

12 Goodlad RA, Al-Mukhtar MYT, Ghatei MA, Bloom SB, Wright NA. Cell proliferation, plasma enteroglucagon and plasma gastrin in starved and refed rats. Virchows Arch [B] 1983; 43: 55-62.

13 Goodlad RA, Lenton W, Ghatei MA, Bloom SR, Wright NA. Effects of an elemental diet, inert bulk and different types of dictary fibre on the response of the intestinal epithelium to refeeding in the rat and relationship to plasma gastrin, enteroglucagon and PYY levels. Gut 1987; 28: 171-80.

14 Sakata T, Yajima T. Influence of short chain fatty acids on the epithelial cell division of digestive tracts. $Q J \operatorname{Exp}$ Physiol 1984; 69: 639-48.

15 Gustafsson BE. Germ-free rearing of rats (general technique). Acta Pathol Microbiol Scand 1948: Suppl LXXIII.

16 Gustafsson BE. Lightweight stainless steel systems for rearing germ-free animals. Ann NY Acad Sci 1959; 78: 17-28.

17 Fuller R. The routine microbiological control of germfree isolators. In: Coates ME, ed. The germ-free animal in research. London: Academic Press, 1968: 37-45.

18 Fuller R. Microbiological monitoring of gnotobiotic isolators. In: Coates ME, Gustafsson $\mathrm{BE}$, eds. The germ-free animal in Biomedical Research. London: Laboratory Animals Ltd, 1984: 111-6.

19 Goodlad RA, Wright NA. Quantitative studies on epithelial replacement in the gut. In: Titchen TA, ed. Techniques in life sciences. Digestive physiology. Vol P2. Ireland: Elsevier Biomedical Press, 1982: 212/1-23.

20 Gustafsson BE. The physiological importance of the colonic microflora. Scand J Gastroenterol 1982; 77 [suppl 77]: 117-31.

21 Sakata T. Effects of indigestible dietary bulk and short chain fatty acids on the tissue weight and epithelial cell proliferation rate of the digestive tract in rats. J Nutr Sci Vitaminol 1986; 32: 355-62.

22 Sakata T. Stimulatory effect of short chain fatty acids on epithelial cell proliferation in the rat small intestine: a possible explanation for trophic effects of fermentable fibre, gut microbes and luminal trophic factors. BrJ Nutr 1987; 58: 95-103.

23 Loeschke K, Resch W. Nucleic acid and protein content of rat caecum mucosa in dietary adaptation - growth by cellular hyperplasia. Pfluegers Arch 1977; 372: 91-4.

24 El-Harith EA, Dickerson JWT, Walker R. Potato starch and caecal hypertrophy in the rat. Fd Cosmet Toxicol 1976; 14: 115-21.

25 Jacobs LR. Effect of dietary fibers on rat large bowel mucosal growth and cell proliferation. Am J Physiol 1984; 246: 378-85.

26 Komai M, Kimura S. Gastrointestinal responses to graded levels of cellulose feeding in conventional and germ-free mice. J Nutr Sci Vitaminol 1980; 26: 389-99. 
27 Savada D. Increased cellular turnover rate of colonic but not duodenal epithelium in mice fed a high-fibre diet. Med Sci Res 1987; 15: 583-4.

28 Savage DC, Seigel JE, Snellen JE, Whitt DD. Transit time of epithelial cells in the small intestine of germ-free mice and ex-germ-free mice associated with indigenous microorganisms. Appl Environ Microbiol 1981; 42: 9961001.

29 Hoensch HP, Steinhardt HJ, Weiss G, Haug D, Maier A, Malchow $H$. Effects of semisynthetic diets on Xenobiotic metabolizing enzyme activity and morphology of small intestinal mucosa in humans. Gastroenterology 1984; 86: 1519-30.

30 Kamath PS, Hoepfner MT, Phillips SF. Short chain fatty acids stimulate motility of the canine ileum. Am J Physiol 1987; 253: 427-33.

31 Church DG. Digestive Physiology of ruminants. Vol 1. Digestive physiology. Oregon: O \& B Books, 1975.

32 Goodlad RA. Some effects of diet on the mitotic index and the cell cycle of the ruminal epithelium of sheep. $Q J$ Exp Physiol 1981; 66: 487-99.
33 Stevens CE, Argenzio RA, Clemens ET. Microbial digestion: rumen versus large intestine. In: Ruckebusch $Y$, Thivend $P$, eds. Digestive physiology and metabolism of ruminants. Lancaster: MTP Press, 1980: 685706.

34 Goodlad RA, Wright NA. Peptides and epithelial growth regulation. Experientia 1987; 43: 780-4.

35 Jacobs LR, Lupton JR. Relationship between colonic luminal $\mathrm{pH}$, cell proliferation and colon carcinogenesis in 1,2-Dimethylhydrazine treated rats fed high fibre diets. Cancer Res 1986; 46: 1727-34.

36 Jacobs LR. Effect of dietary fibre on colonic cell proliferation and its relationship to colon carcinogenesis. Prev Med 1987; 16: 566-71.

37 Reddy BS, Maeura Y, Wayman M. Effects of dietary corn bran and autohydrolyzed lignin on 3,2'-dimethyl-4aminobiphenyl-induced intestinal carcinogenesis in male F344 rats. JNCI 1983; 71: 419-23.

38 Galloway DJ, Jarrett F, Boyle P, et al. Morphological and cell kinetic effects of dietary manipulation during colorectal carcinogenesis. Gut 1987; 28: 754-63. 